\title{
Epidemiological Features of the Bladder Neck Rest Position and Mobility
}

\author{
Edyta Horosz ${ }^{1}$, Andrzej Pomian ${ }^{1}$, Aneta Zwierzchowska ${ }^{1}$, Wojciech Lisik ${ }^{2} \mathbb{0}$, \\ Wojciech Majkusiak ${ }^{1}$, Paweł Tomasik ${ }^{1}$, Beata Rutkowska ${ }^{1}$, Joana Skalska ${ }^{1}$, \\ Małgorzata Siemion ${ }^{1}$, Dominika Banasiuk ${ }^{1}$ and Ewa Barcz ${ }^{1, *}$ \\ 1 Department of Obstetrics and Gynecology, Multidisciplinary Hospital Warsaw-Miedzylesie, 04-749 Warsaw, \\ Poland; edytahorosz@o2.pl (E.H.); apomian@gmail.com (A.P.); a.j.zwierzchowska@gmail.com (A.Z.); \\ wmajkusiak@gmail.com (W.M.); p_tomasik@wp.pl (P.T.); beata_zak@interia.pl (B.R.); \\ joanajermak@gmail.com (J.S.); siemion.malgorzata@gmail.com (M.S.); dominika.ochedalska@wp.pl (D.B.) \\ 2 Department of General and Transplantation Surgery, Medical University of Warsaw, 00-001 Warsaw, Poland; \\ wojciech.lisik@wum.edu.pl \\ * Correspondence: ewa-barcz@mssw.pl; Tel.: +48-22-473-5335
}

Received: 29 June 2020; Accepted: 21 July 2020; Published: 28 July 2020

check for updates

\begin{abstract}
The data concerning epidemiological determinants of the bladder neck (BN) mobility are scarce. The aim of the study was to determine epidemiological features and identify factors influencing BN position at rest and BN mobility in patients without pelvic organ prolapse (POP). Seven hundred and ninety-six patients that attended two outpatient clinics were enrolled in the study. Position and mobility of the BN were measured with the use of pelvic floor ultrasound. Demographic and functional factors that were hypothesized to influence BN mobility were assessed. Vaginal deliveries (VDs) and age $\geq 65$ were associated with lower BN position at rest. Higher BN mobility was observed in women with stress urinary incontinence (SUI). In obese women, higher BN position and lower BN mobility was observed compared to non-obese women, and it was correlated with longer urethras in this group of patients. VDs and their number were associated with increased BN mobility, independently of body mass index (BMI). To conclude, obesity, VDs, and age are factors associated with changes in bladder neck position at rest and its mobility. Higher BMI correlates with restricted BN mobility, and, therefore, the incidence of SUI in obese patients is probably not connected to BN hypermobility.
\end{abstract}

Keywords: bladder neck mobility; urethral mobility; ultrasound; female urethra

\section{Introduction}

The female urethra is a part of the urinary tract passing from the internal orifice at the bladder neck (BN) to external urethral orifice in the vaginal vestibule. Urethral length ranges from 19 to $51 \mathrm{~mm}$, the mean length equaling $30 \mathrm{~mm}$. Approximately $30 \%$ of the female population is characterized by a statistically significantly shorter or longer urethra than the average $30 \mathrm{~mm}$ [1].Tubular structure of the urethra is a histological continuation of the vesical trigone and is composed of two smooth muscle layers that are present throughout the upper four-fifths of the urethra: an inner thick longitudinal smooth muscle layer and an outer thin circular smooth muscle layer [2]. The external striated muscle part of the urethra is called the external urethral sphincter. It extends from the neck to the perineal membrane and accounts for $20-80 \%$ of the total urethral length, with the thickest part in the middle third of the urethra, the high-pressure zone [3]. The BN consists of the distal portion of the detrusor (including the trigone) and continues into the proximal urethra [2]. 
The functional anatomy of the BN and urethra has been studied extensively because of the belief that it is important for urinary continence. To date, the pathophysiology of stress urinary incontinence (SUI) has not been fully explained and the gaps in the understanding of causal mechanisms limit progress both in preventive strategies and treatment. A number of factors seem to contribute to the etiology of this condition, involving pathologies of the urethral sphincter function, bladder neck, urethra and pelvic floor muscles. However, the predominant factor influencing the occurrence of SUI remains to be elucidated $[4,5]$. Increased BN mobility is regarded to have an association with the occurrence of SUI [6]. It has been suggested that this results from disturbed BN and urethral support [7,8], which can be associated with pregnancy and vaginal birth [9]. During the last few decades, a variety of methods have been used to assess urethra-vesical mobility, including the Q-tip test [10] and radiographic techniques [11], as well as ultrasound techniques-introital [12], vaginal [13] or perineal [14] and magnetic resonance imaging [15]. BN descent has been postulated to be the most appropriate measure of urethral mobility [16]. It can be evaluated with the use of ultrasound examination: a non-invasive, simple and reproducible method that allows for dynamic assessment of pelvic organs. To date, several studies evaluating changes in BN mobility during pregnancy, after childbirth and its correlation to urinary incontinence have been published $[9,17,18]$. Still, BN hypermobility has also been reported in asymptomatic nonpregnant nulliparous women $[19,20]$, as well as patients with pelvic organ prolapse (POP), both with and without any symptoms. Although the functional anatomy of the BN has been studied extensively, the available data concerning epidemiological determinants of urethro-vesical mobility are scarce.

The aim of the study was to determine epidemiological features and identify the independent factors influencing BN position and mobility in patients without POP.

\section{Materials and Methods}

The study was performed during the years 2017-2020. A cohort of 796 patients attending the outpatient clinic of the Department of Obstetrics and Gynecology in Multidisciplinary Hospital WarsawMiedzylesie and the outpatient bariatric clinic of the Department of General and Transplantation Surgery, Medical University of Warsaw were recruited to the study. The exclusion criteria were: previous prolapse and incontinence surgery, coexisting pelvic organ prolapse (POPQ $>1$ ).

Various factors that were hypothesized to influence BN mobility were assessed: age, body mass index (BMI), height, parity, mode of delivery, birth weight of children, and age at the time of first delivery.

All women underwent pelvic floor ultrasound examination. Urethral length and BN position were measured in a standardized manner, with the patient on the gynecological chair in a semi-sitting position with the bladder filled to $200-400 \mathrm{~mL}$. Three diameters of the bladder were measured in order to estimate the bladder volume before the examination. The probe (a $3.6-8.3 \mathrm{MHz}$ vaginal transducer with a beam angle of $160^{\circ}$ ) was placed in the vaginal introitus at the level of the external urethral orifice. With the probe in this position, the urinary bladder, urethra, and pubic symphysis with the interpubic disc were visualized in the median sagittal plane, according to Interdisciplinary S2k Guideline: Sonography in Urogynecology [21]. The length of the hypoechogenic core of the urethra was measured from the BN to the pelvic diaphragm. This method of measurement has been proven to be highly repeatable and reproducible [22]. BN position at rest was measured as the shortest distance between the urethral-bladder junction and the horizontal line running through the lower edge of symphysis pubis and was shown in millimeters. Accordingly, BN position was measured in the maximal descent during the Valsalva maneuver (VM) (Figure 1).

$\mathrm{BN}$ mobility was defined as the difference between its position at rest and during the VM and was shown in millimeters.

The study was approved by the ethics committee of Medical University of Warsaw (KB/150), and all study participants gave written informed consent.

Descriptive statistical analysis expressing the quantitative and categorical variables was performed with the use of $\mathrm{R}$ version 4.0.0 software. Normality was tested using the Lillefors and Shapiro-Wilk $\mathrm{W}$ tests. We associated the degree and type of non-adherence using the $\mathrm{T}$ test and variance analysis 
(ANOVA). The Pearson correlation test was used to determine correlations between quantitative variables. Multiple regression analysis was used to present multivariate relationships and to show the influence of independent variables on a dependent variable. $p$-value $<0.05$ was considered statistically significant.

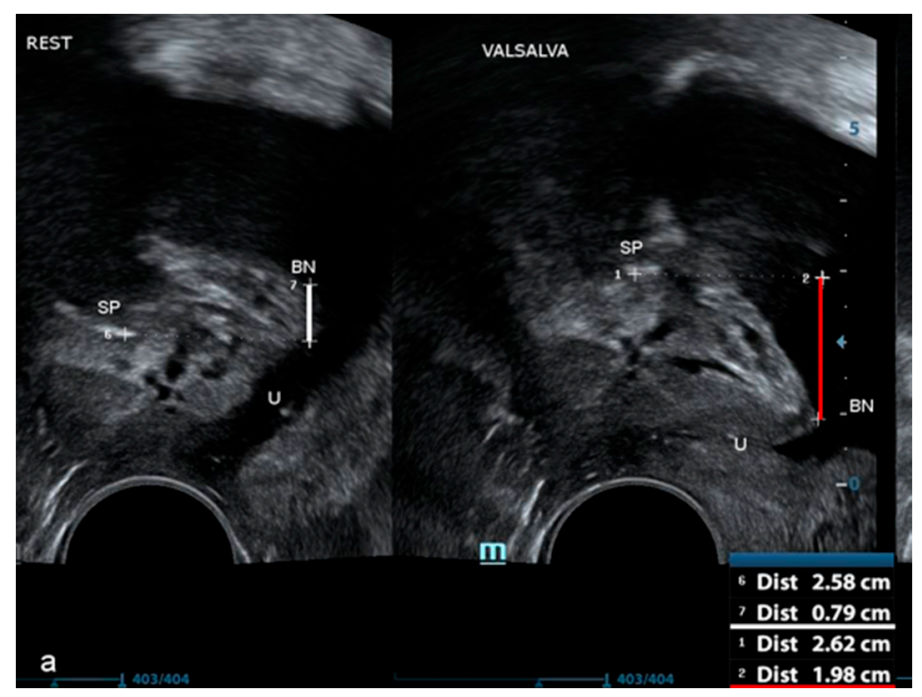

Figure 1. The technique of bladder neck (BN) position measurement.

\section{Results}

Seven hundred and ninety-six women were enrolled in the study. The mean age of the patients was $55.2 \pm 12.8$ years. The mean BMI was $29.4 \pm 7.0$. Among 796 patients, 352 were obese (BMI $\geq 30$, as defined by the World Health Organization).

Baseline characteristics of the study group are shown in Table 1.

Table 1. Cohort description and analyzed demographic features $(n=796)$.

\begin{tabular}{ccccc}
\hline Variable & Mean & Minimum & Maximum & Standard Deviation \\
\hline Age (years) & 53.4 & 18.0 & 85.0 & 13.3 \\
Height (cm) & 164.2 & 145.0 & 190.0 & 6.1 \\
Weight (kg) & 85.6 & 44.0 & 176.0 & 25.3 \\
BMI & 31.7 & 16.6 & 70.5 & 8.8 \\
No of deliveries & 1.9 & 0.0 & 10.0 & 1.1 \\
No of VDs & 1.7 & 0.0 & 10.0 & 1.2 \\
No of cesarean sections & 0.2 & 0.0 & 3.0 & 0.5 \\
No of vacuum/forceps deliveries & 0.0 & 0.0 & 2.0 & 0.1 \\
Average birth weight (VDs only) (g) & 3432 & 650 & 5050 & 500 \\
Maximum birth weight (VDs only) (g) & 3602 & 650 & 5850 & 555 \\
Cumulative birth weight (VDs only) (g) & 7045 & 650 & 30,800 & 3460 \\
Age at 1st VD (years) & 23.9 & 14.0 & 40.0 & 4.9 \\
Age at 2nd VD (years) & 27.5 & 15.0 & 43.0 & 5.3 \\
Age at last VD (years) & 28.6 & 17.0 & 46.0 & 4.3 \\
Urethral length (mm) & 30.2 & 19.0 & 48.1 & 7.0 \\
BN position at rest (mm) & 10.0 & -31.8 & 29.9 & 9.3 \\
BN position during the VM & -4.8 & -37.1 & 24.8 & 7.1 \\
BN mobility (rest-VM) (mm) & 14.9 & 0.3 & 42.9 & \\
\hline
\end{tabular}

BMI-body mass index; BN—bladder neck; VD—vaginal delivery; VM-Valsalva maneuver.

The mean length of the urethra in the whole study group was $30.2 \pm 4.3 \mathrm{~mm}$. The mean position of the $\mathrm{BN}$ at rest was $10 \pm 7.0 \mathrm{~mm}$. The mean $\mathrm{BN}$ position during the $\mathrm{VM}$ was $-4.8 \pm 9.3 \mathrm{~mm}$, whereas the mean $\mathrm{BN}$ was $14.9 \pm 7.1 \mathrm{~mm}$. 
BN position at rest was analyzed in the whole study group, as well as relative to all available demographic features listed in Table 1. It was demonstrated that BN position was statistically significantly lower in non-obese women compared to the obese. VDs and older age were associated with lower BN position in the whole study group. As obesity is often connected with pelvic floor disorders, we performed the comparative analysis of obese and non-obese women and we showed that in both groups VDs and age over 65 years were associated with lower BN position at rest (Table 2).

Table 2. Bladder neck position at rest, during the Valsalva maneuver, and bladder neck mobility in examined groups of patients.

\begin{tabular}{|c|c|c|c|}
\hline Position Patients & At Rest $[\mathrm{mm}]$ & During the VM [mm] & BN Mobility (rest-VM) [mm] \\
\hline $\begin{array}{c}\text { Whole Group } \\
n=796\end{array}$ & $10.0 \pm 7.0$ & $-4.8 \pm 9.3$ & $14.9 \pm 7.1$ \\
\hline $\begin{array}{l}\text { Obese } \\
n=352\end{array}$ & $11.7 \pm 6.8$ & $-2.0 \pm 9.6$ & $13.6 \pm 7.4$ \\
\hline $\begin{array}{c}\text { Non-Obese } \\
n=444\end{array}$ & $8.7 \pm 6.9$ & $-7.1 \pm 8.5$ & $15.8 \pm 6.6$ \\
\hline$p$ & $<0.001$ & $<0.001$ & $<0.001$ \\
\hline $\begin{array}{c}\text { No of VDs }=0 \\
n=146\end{array}$ & $13.4 \pm 6.0$ & $1.3 \pm 8.5$ & $12.1 \pm 6.7$ \\
\hline $\begin{array}{c}\text { No of VDs }>0 \\
n=650\end{array}$ & $9.2 \pm 7.0$ & $-6.2 \pm 8.9$ & $15.5 \pm 7.0$ \\
\hline$p$ & $<0.001$ & $<0.001$ & $<0.001$ \\
\hline $\begin{array}{c}<65 \text { years } \\
n=613\end{array}$ & $11.1 \pm 6.4$ & $-4.1 \pm 9.2$ & $15.1 \pm 7.2$ \\
\hline $\begin{array}{c}\geq 65 \text { years } \\
n=182\end{array}$ & $6.4 \pm 7.7$ & $-7.4 \pm 9.1$ & $13.8 \pm 6.3$ \\
\hline$p$ & $<0.001$ & $<0.001$ & $<0.05$ \\
\hline $\begin{array}{l}\text { Obese with VD }=0 \\
n=102\end{array}$ & $14.5 \pm 5.9$ & $3.3 \pm 7.8$ & $11.2 \pm 6.3$ \\
\hline $\begin{array}{c}\text { Obese with VD }>0 \\
n=250\end{array}$ & $10.5 \pm 6.8$ & $-4.1 \pm 9.3$ & $14.6 \pm 7.6$ \\
\hline$p$ & $<0.001$ & $<0.001$ & $<0.001$ \\
\hline $\begin{array}{l}\text { Non-obese with } \mathrm{VD}=0 \\
\qquad n=44\end{array}$ & $10.8 \pm 5.4$ & $-3.4 \pm 8.0$ & $14.2 \pm 7.2$ \\
\hline $\begin{array}{l}\text { Non-obese with VD }>0 \\
\qquad n=400\end{array}$ & $8.5 \pm 7.0$ & $-7.6 \pm 8.4$ & $16 \pm 6.5$ \\
\hline$p$ & $<0.05$ & $<0.01$ & Ns \\
\hline $\begin{array}{c}\text { Obese }<65 \text { years } \\
n=281\end{array}$ & $12.8 \pm 6.3$ & $-1.1 \pm 9.6$ & $13.9 \pm 7.8$ \\
\hline $\begin{array}{c}\text { Obese } \geq 65 \text { years } \\
n=71\end{array}$ & $7.0 \pm 6.8$ & $-5.5 \pm 8.1$ & $12.5 \pm 5.5$ \\
\hline$p$ & $<0.001$ & $<0.001$ & Ns \\
\hline $\begin{array}{c}\text { Non-obese }<65 \text { years } \\
\qquad n=332\end{array}$ & $9.6 \pm 6.2$ & $-6.6 \pm 8.1$ & $16.2 \pm 6.5$ \\
\hline $\begin{array}{c}\text { Non-obese } \geq 65 \text { years } \\
n=111\end{array}$ & $6.1 \pm 8.2$ & $-8.6 \pm 9.4$ & $14.7 \pm 6.6$ \\
\hline$p$ & $<0.001$ & $<0.05$ & $<0.05$ \\
\hline
\end{tabular}

Data are given as mean, \pm SD; BN—bladder neck; VD—vaginal delivery; VM—Valsalva maneuver; ns—not significant. 
It can also be seen that the BN position during the VM was highly statistically significantly higher in obese women compared to women with normal body weight $(p<0.001)$. On the contrary, both VDs and age were connected with lower $\mathrm{BN}$ position during the VM.

$\mathrm{BN}$ mobility was lower in obese patients compared to non-obese women. Meanwhile, vaginal birth was associated with increased BN mobility when compared to nulliparae.

In the subgroup of obese women, VDs were associated with increased BN mobility, whereas, in the non-obese patients, after VDs, the increase of BN mobility was not statistically significant. Age did not influence BN mobility in obese patients. Meanwhile, in the subgroup of non-obese patients BN mobility was lower in older patients but the difference was not highly significant (Table 2).

Since we previously showed that urethral length is associated with BMI [1], an analysis of correlations between BMI and urethral length and BN mobility was performed. A highly statistically significant negative correlation was observed. Lower BN mobility is associated with increased BMI and urethral length (Figure 2).

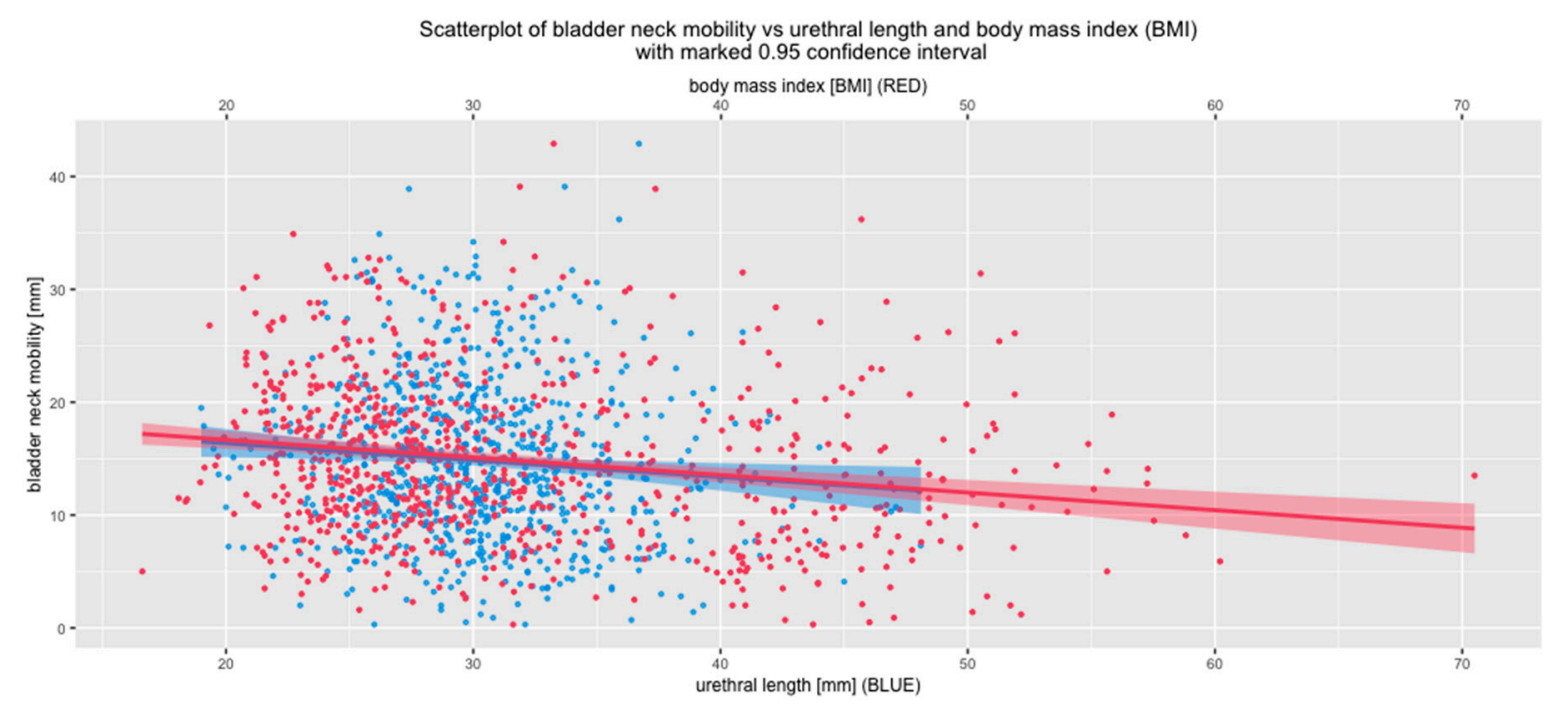

Figure 2. Associations between bladder neck mobility, urethral length, and body mass index (BMI).

Since increased BN mobility has been acknowledged as one of the risk factors of stress urinary incontinence (SUI), BN position, both at rest and during the VM, as well as BN mobility, were compared in women that required surgical treatment for SUI and women without SUI or presenting with sporadic leak, not requiring anti-incontinence procedures. A lower BN position at rest and during the VM was observed in women with SUI. BN mobility was statistically significantly higher in women with SUI compared to women that were continent (Table 3).

Table 3. Bladder neck position at rest, during the Valsalva maneuver, and bladder neck mobility in patient with stress urinary incontinence (SUI) that required anti-incontinence procedures compared to women without SUI or with minor incontinence not requiring surgical intervention.

\begin{tabular}{|c|c|c|c|}
\hline BN Position & $\begin{array}{l}\text { At Rest } \\
{[\mathrm{mm}]}\end{array}$ & $\begin{array}{l}\text { During the } \\
\text { VM [mm] }\end{array}$ & $\begin{array}{c}\text { BN Mobility } \\
\text { (Rest-VM) }[\mathrm{mm}]\end{array}$ \\
\hline $\begin{array}{l}\text { Not scheduled for anti-incontinence } \\
\text { surgery } \\
n=426\end{array}$ & $11.1 \pm 7.7$ & $-2.7 \pm 10.3$ & $13.8 \pm 7.2$ \\
\hline $\begin{array}{l}\text { Scheduled for anti-incontinence surgery } \\
\qquad n=370\end{array}$ & $8.7 \pm 5.8$ & $-7.4 \pm 7.2$ & $16.1 \pm 6.8$ \\
\hline$p$ & $p<0.001$ & $p<0.001$ & $p<0.001$ \\
\hline
\end{tabular}

Data are given as mean, $\pm \mathrm{SD}$; $\mathrm{BN}$-bladder neck; VM—Valsalva maneuver. 
Taking into consideration the results listed above, correlations between BN mobility and recognized risk factors for SUI and POP were investigated.

A highly statistically significant positive correlation between the number of VDs and increased BN mobility was observed (Figure 3).

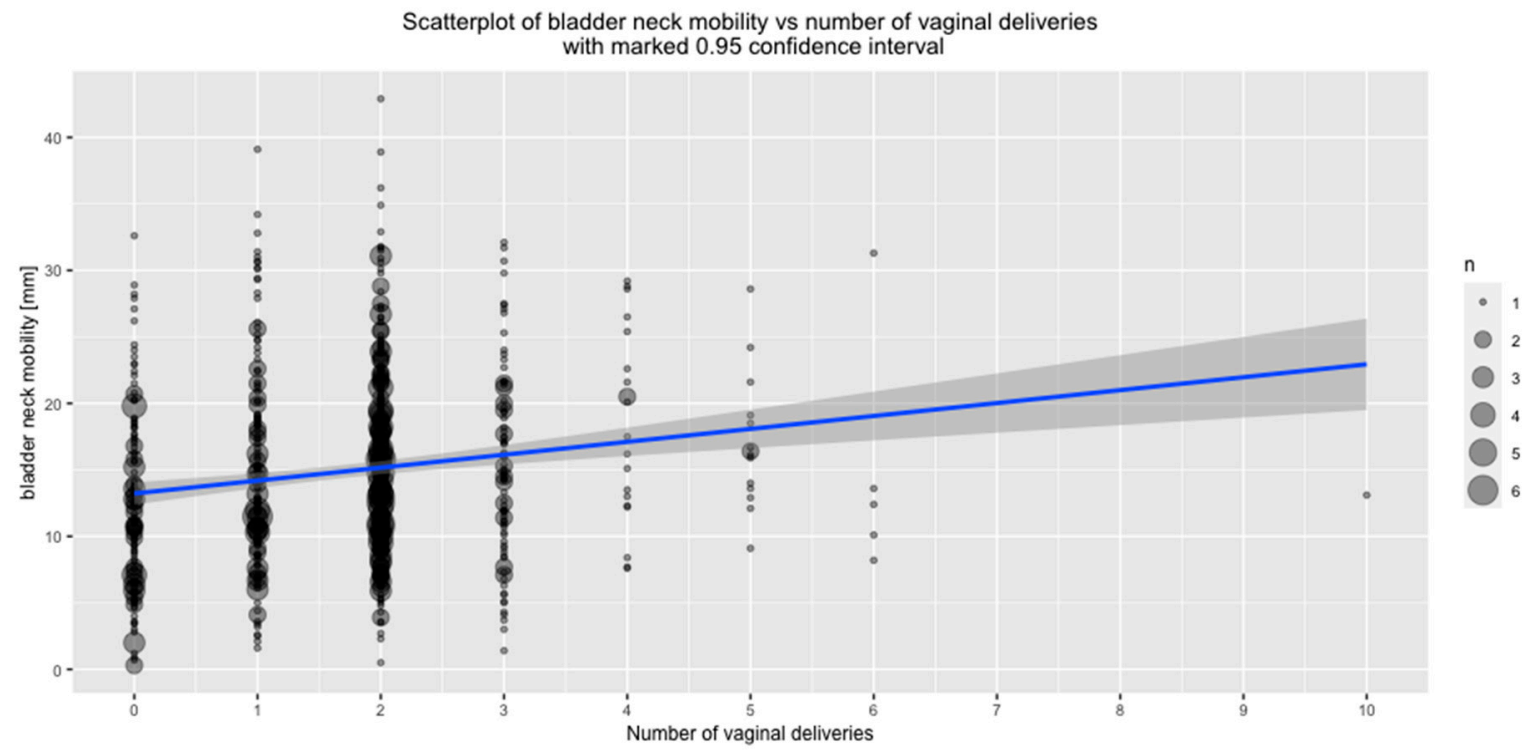

Figure 3. Correlation between bladder neck mobility and number of vaginal deliveries.

Associations between BN mobility and the number of VDs were also assessed relative to BMI. Both in the subgroup of women with BMI $<30$ and in the subgroup of obese women, the number of vaginal deliveries correlated positively with $\mathrm{BN}$ mobility. However, in the obese group, VDs were associated with a significantly greater increase in BN mobility compared to non-obese women (BMI < 30) (Figure 4).

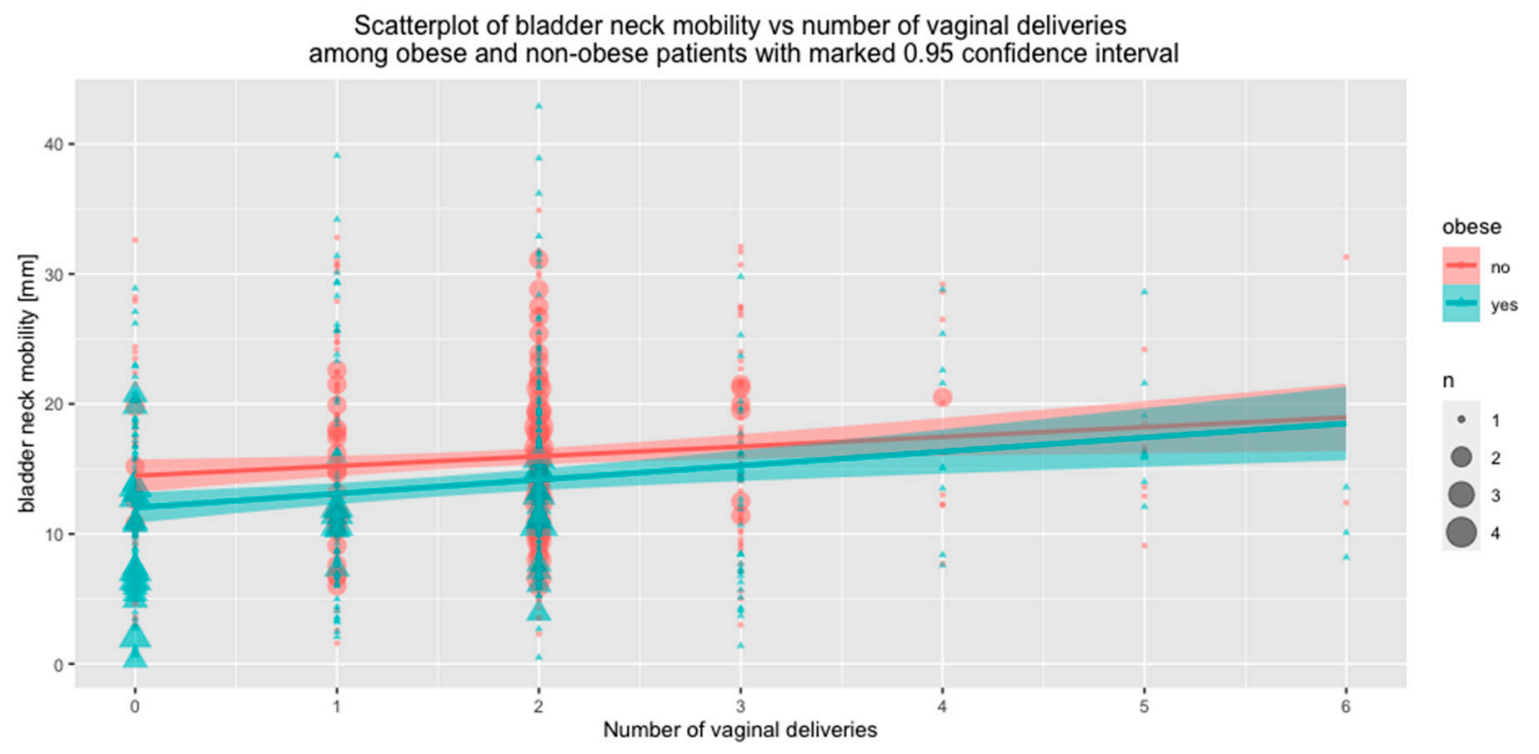

Figure 4. Correlation between the number of vaginal deliveries and bladder neck mobility in non-obese and obese women $(p<0.001)$.

BN mobility correlated negatively with BMI $(p<0.01)$ (Figure 5). 


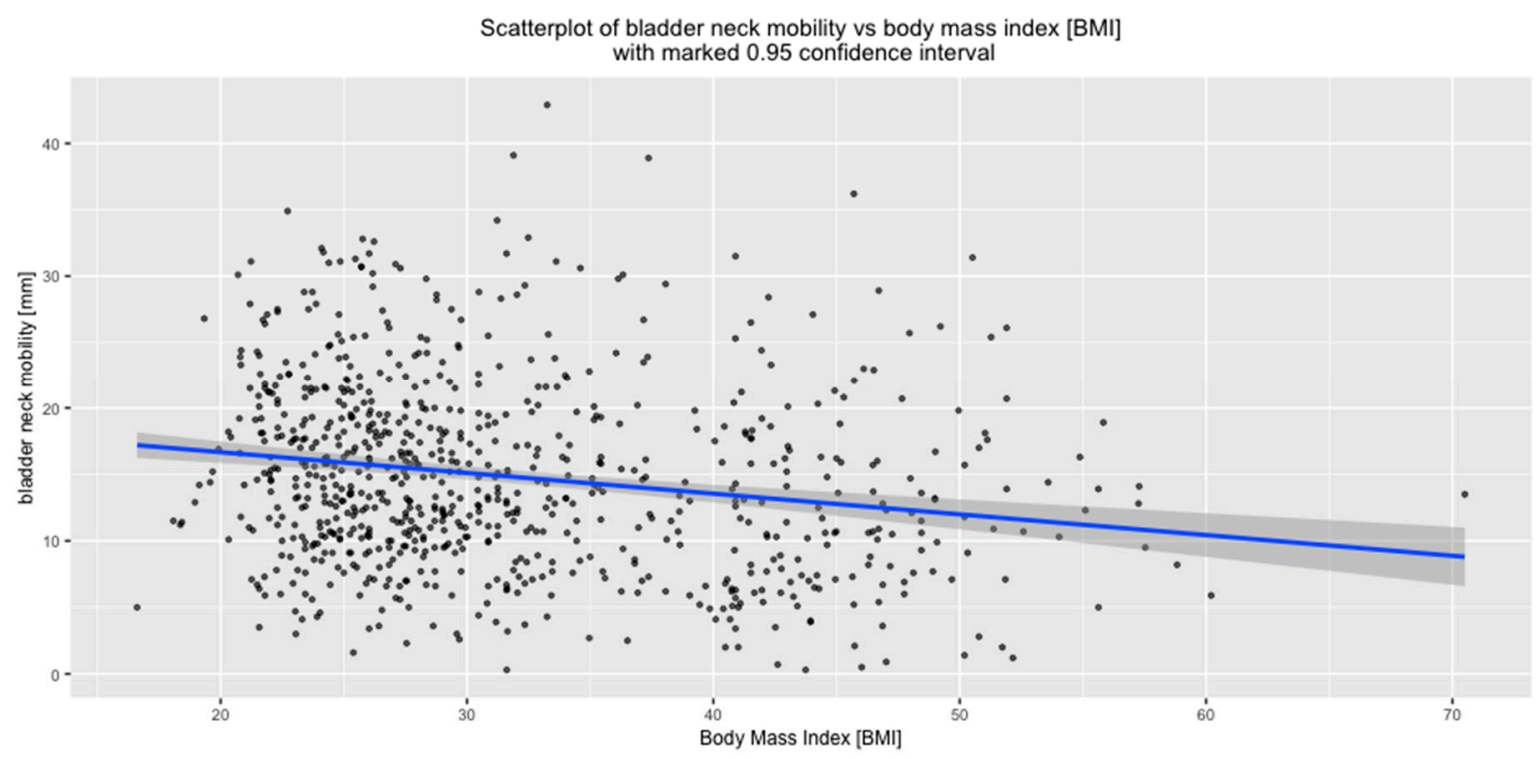

Figure 5. Correlation between BN mobility and BMI.

The impact of BMI on BN mobility was also analyzed separately for the subgroups of non-obese and obese women. In both subgroups, BN mobility correlated negatively with BMI. $(p<0.01)$ (Figure 6$)$.

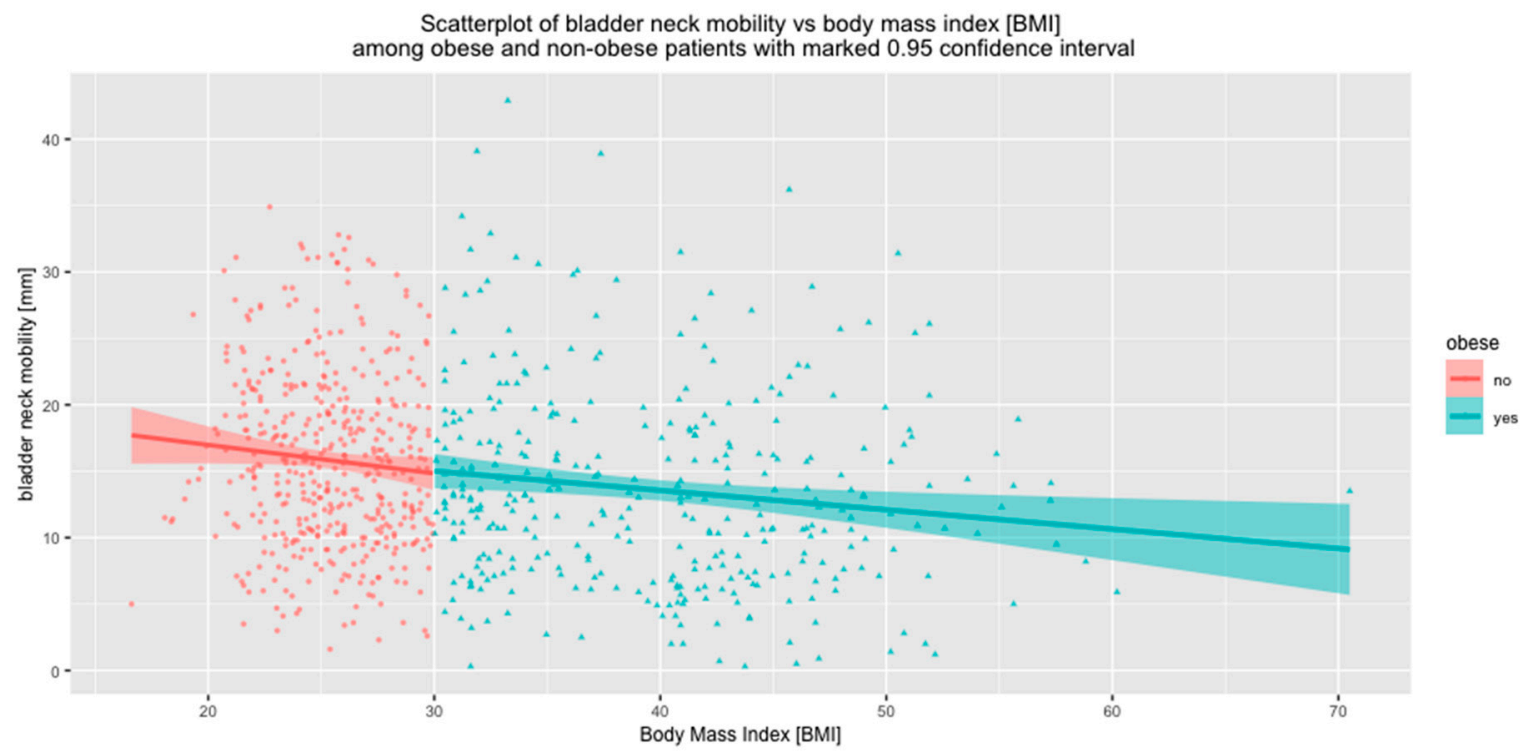

Figure 6. Correlation between BN mobility and BMI in subgroups of non-obese and obese women.

The correlations between BMI and BN mobility were also investigated in the subgroups of women who had had VDs, with regard to the number of VDs. It was shown that the influences of BMI and VDs on BN mobility are independent. With increased BMI, BN mobility decreased, independent of the number of VDs ( $p<0.001$ in all subgroups) (Figure 7).

No correlations between BN mobility and height, birth weight of the delivered children, maximum birth weight of the delivered children, nor age at first delivery were observed, neither in the whole study group nor in the subgroups of women with normal body weight, overweight, and obese women. 


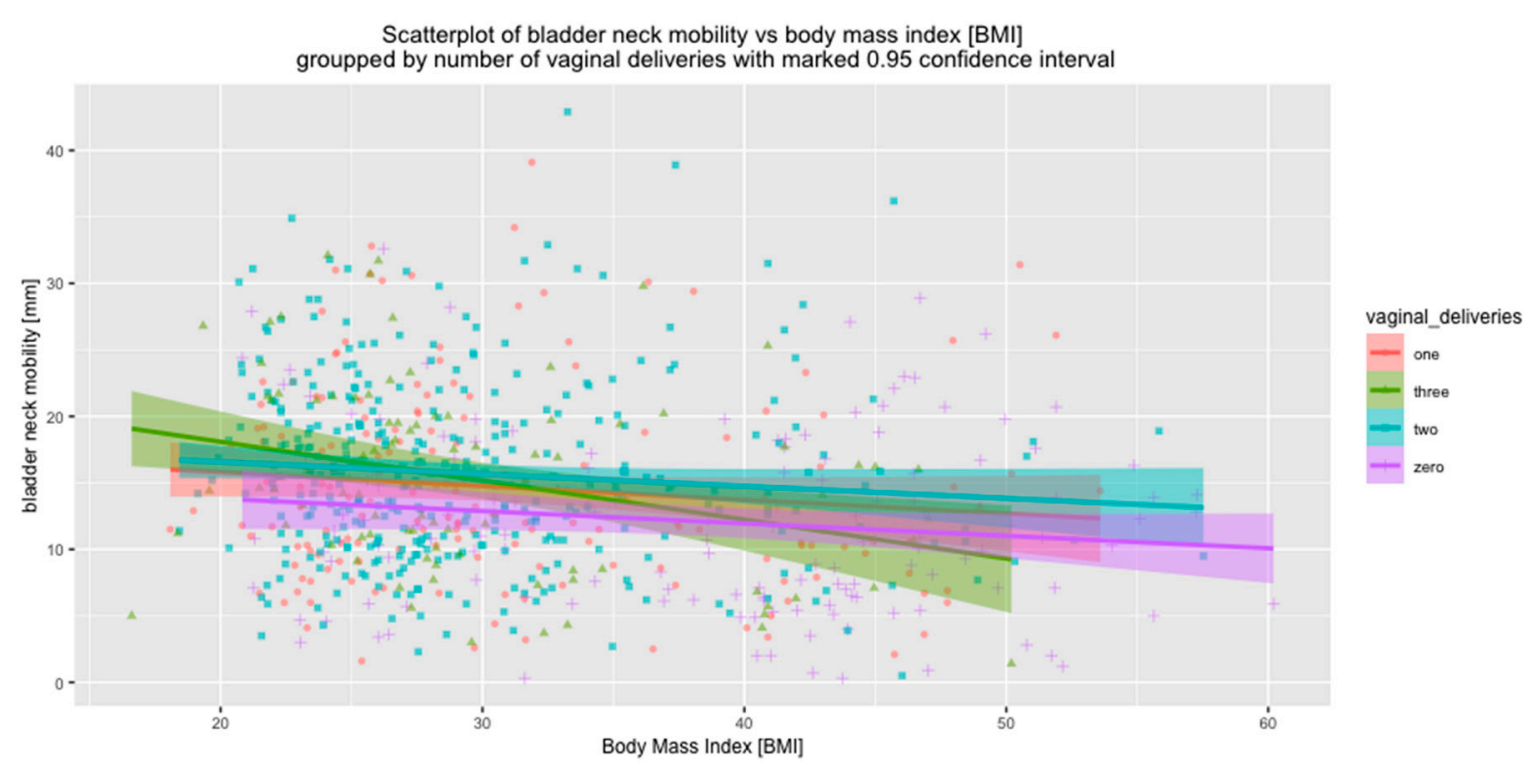

Figure 7. Correlation between bladder neck mobility and BMI, relative to the number of vaginal deliveries.

\section{Discussion}

The urethra and $\mathrm{BN}$ are considered a synergic unit due to the fact that their anatomy and function work co-dependently. While attempts have been made to define normal BN mobility and hypermobility, the available literature does not provide data on the relationship between the BN mobility and demographic characteristics of patients. Excessive urethral mobility may be observed in women who do not suffer from any pelvic floor disorder. However, a relationship between BN hypermobility and the occurrence SUI has been reported [4,6]. The present study confirms these findings, since greater BN mobility was shown in patients requiring surgery for SUI compared to women without SUI.

Taking into consideration the literature data, as well as our own observations, we have made an attempt to evaluate demographic factors influencing the BN position and mobility, including the most important factors connected with SUI, such as VDs, age, obesity, birth weight of children, and age during first delivery. Since several studies repeatedly demonstrated an increased prevalence of pelvic floor disorder (PFD) among obese women [23], obesity was analyzed as an independent risk factor.

Compared to perineal or suprapubic approach, ultrasound assessment of the urethra by introital technique proves to be a safe, rapid and efficacious method that can be applied also to evaluate other urethral diseases, e.g., inflammatory pathologies, such as urethral diverticula or neoplasms [24,25].

In our study, the bladder volume during the assessment was $200-400 \mathrm{~mL}$. As we had previously shown, the associations between the bladder filling parameters of the urethra measured in the volume range of $200-400 \mathrm{~mL}$ are not statistically significant [1].

Many authors tried to distinguish the limits of normality for pelvic floor ultrasound parameters of the BN mobility. Peschers et al. examined 39 women aged 18-36. BN mobility varied from 4 to 32 mm during coughing and from 2 to $31 \mathrm{~mm}$ during the VM [20], whereas Reed et al. demonstrated lower BN mobility, i.e., between 0 and $18.7 \mathrm{~mm}$ (mean $6.3 \mathrm{~mm}$ ) in 48 asymptomatic non-pregnant nulliparous volunteers [19]. By contrast, another study of one 118 young nulligravid women showed a wide range of $\mathrm{BN}$ descent from 1.2 to $40.2 \mathrm{~mm}$ (mean $17.4 \mathrm{~mm}$ ) [26]. The same group of authors described 178 nulliparous Caucasian female twins and their sisters, suggesting significant congenital contribution to the phenotype of BN mobility, with approximately $50 \%$ of variability due to genetic factors in nulligravid women. [27]. Naranjo-Ortiz et al. analyzed functional BN anatomy in a retrospective study in which 429 women that underwent urodynamic testing were enrolled. Considering its association with SUI, the authors suggested a cutoff of $25 \mathrm{~mm}$ for BN descent to define as abnormal [16]. In the current study, we analyzed BN position and mobility in a group of 796 patients. To our knowledge, it is the 
largest analysis published to date. BN position at rest was assessed in all women. Demographic factors potentially associated with this parameter were also investigated. Both age and VDs were associated with lower BN position at rest. The mean BN position in the whole group was $10.0 \pm 7.0 \mathrm{~mm}$. In an analysis performed by Jundt et al., no significant differences between the BN position before and after delivery were observed in one hundred twelve primiparous women [6]. In our study, the position of BN was significantly lower in the group of women who delivered vaginally than in nulliparous patients. The discrepancy may result from a larger sample size in our study and the fact that in the above cited study sonographic examination was performed a few months after delivery, whereas in the current analysis patients with a history of VD were included regardless to the time that passed after their deliveries.

In the current analysis, we showed that BN position at rest decreases with age and is lower in women aged 65 or over compared to younger patients. This is in agreement with other authors, who indicated age as a risk factor for both POP and SUI [28].

We also demonstrated that in obese patients the position of the $\mathrm{BN}$ at rest is higher than in non-obese women. We had previously reported that this phenomenon is connected with significantly longer urethras in obese patients [1].

In order to assess BN mobility in the analyzed population, we took into consideration demographic factors that may affect this parameter, i.e., number of deliveries, age, BMI, height, and medium and maximum birth weight of children, as well as age during the first delivery. Only the first three factors were proven to influence BN mobility.

Pregnancy and childbirth are risk factors for SUI. The occurrence of SUI is higher after VD than after cesarean section [29]. This may be the result of congenital factors, hormonal changes, or neuromuscular damage to the urethral support structures. Most studies investigated changes of the position and mobility of the urethro-vesical junction during the third trimester of pregnancy and several weeks to six months postpartum in relation to incontinence. Toozs-Hobson et al. studied 110 primigravid women recruited between 32 weeks and term and who completed the 6-months' follow-up. Compared to antenatal measurements, VD was associated with increased BN mobility and lower BN position [30]. This is with agreement with a prospective observational study performed by Dietz and Bennett, who examined 169 nulliparous women at 6-18 weeks, 32-37 weeks, and 2-5 months after childbirth. VD was associated with significantly increased mobility of the proximal urethra and $\mathrm{BN}$, as well as decreased BN position. Forceps delivery was connected with the most pronounced effect [31]. One of the longest observations assessing $\mathrm{BN}$ and urethral mobility from pregnancy to 4 years postpartum included 180 women and confirmed the abovementioned associations between vaginal delivery and $\mathrm{BN}$ descent and mobility. Again, operative vaginal deliveries proved to have the strongest correlation with hypermobility of these structures. The authors reported increased values for all ultrasound variables over time, especially during the interval between 1 and 4 years after delivery [9].

In the present study, we confirmed that vaginal childbirths increase BN mobility and that BN mobility was positively correlated with the number of deliveries. This outcome was independent of BMI. Our results are consistent with those obtained by authors cited above. Large sample size and the fact that obesity was analyzed as an independent risk factor may be considered the strengths of the current study.

Despite the fact that women aged 65 or over had a lower BN position, BN mobility did not increase with age. According to the literature, the risk of SUI is positively correlated with age [28,32]. Our results suggest that this phenomenon may not be a result of increased BN mobility in older women.

In the current study, urethral mobility decreased with increasing BMI, and this effect was observed in the whole study group, both women with normal weight and obese patients. This is certainly related to significantly longer urethras [1] and higher BN position at rest in obese patients shown in the current study. It is widely agreed that obesity influences various kinds of lower urinary tract symptoms, including SUI. Associations between BMI and urinary incontinence were evaluated in several studies $[33,34]$. The results of the present study implicate that the higher occurrence of SUI in obese patients is not related to BN mobility. Presumably, urethral sphincter deficiency and the higher intra-abdominal pressure are the primary factors responsible for stress incontinence in those women. 


\section{Conclusions}

VDs and age over 65 were identified as demographic factors associated with lower BN position at rest. On the contrary, obesity is associated with higher $\mathrm{BN}$ position, and it is dependent on the longer urethra in these women as compared to non-obese women.

Higher mobility of the $\mathrm{BN}$ was observed in women requiring medical intervention because of SUI as compared to continent patients, confirming importance of this factor in the pathophysiology of SUI. We also showed that VDs and their number positively correlated with BN mobility and that the phenomenon was independent of BMI, which confirms delivery-dependent urethral hypermobility. We demonstrated that obesity is correlated with restriction of the BN mobility and strongly connected to urethral length. These findings may suggest that higher incidence of SUI in obese patients is not associated with hypermobility of BN.

Author Contributions: Conceptualization, E.B. and E.H.; Methodology, A.P.; Software, A.P. and P.T.; Validation, W.M., P.T. and J.S.; Formal Analysis, P.T.; Investigation, A.Z., B.R., E.H. and P.T.; Resources, J.S., M.S., W.L. and D.B.; Data Curation, W.M., W.L.; Writing-Original Draft Preparation, E.H. and E.B.; Writing-Review \& Editing, E.B. and A.Z.; Visualization, W.M. and A.Z.; Supervision, E.B.; Project Administration, E.B.; Funding Acquisition, NA. All authors have read and agreed to the published version of the manuscript.

Funding: This research received no external funding.

Conflicts of Interest: The authors declare no conflict of interest

\section{References}

1. Pomian, A.; Majkusiak, W.; Kociszewski, J.; Tomasik, P.; Horosz, E.; Zwierzchowska, A.; Lisik, W.; Barcz, E. Demographic features of female urethra length. Neurourol. Urodyn. 2018, 37, 1751-1756. [CrossRef] [PubMed]

2. Huisman, A.B. Aspects on the anatomy of the female urethra with special relation to urinary continence. Contrib. Gynecol. Obstet. 1983, 10,1-31. [PubMed]

3. Ashton-Miller, J.A.; DeLancey, J.O. Functional anatomy of the female pelvic floor. Ann. N. Y. Acad. Sci. 2007, 1101, 266-296. [CrossRef] [PubMed]

4. Pirpiris, A.; Shek, K.L.; Dietz, H.P. Urethral mobility and urinary incontinence. Ultrasound Obstet. Gynecol. 2010, 36, 507-511. [CrossRef]

5. DeLancey, J.O.; Trowbridge, E.R.; Miller, J.M.; Morgan, D.M.; Guire, K.; Fenner, D.E.; Weadock, W.J.; Ashton-Miller, J.A. Stress urinary incontinence: Relative importance of urethral support and urethral closure pressure. J. Urol. 2008, 179, 2286-2290. [CrossRef]

6. Jundt, K.; Scheer, I.; Schiessl, B.; Karl, K.; Friese, K.; Peschers, U.M. Incontinence, bladder neck mobility, and sphincter ruptures in primiparous women. Eur. J. Med. Res. 2010, 15, 246-252. [CrossRef]

7. DeLancey, J.O. Structural support of the urethra as it relates to stress urinary incontinence: The hammock hypothesis. Am. J. Obstet. Gynecol. 1994, 170, 1713-1720. [CrossRef]

8. Petros, P.E.; Ulmsten, U.I. An integral theory of female urinary incontinence. Experimental and clinical considerations. Acta Obstet. Gynecol. Scand. Suppl. 1990, 153, 7-31. [CrossRef]

9. Volløyhaug, I.; van Gruting, I.; van Delft, K.; Sultan, A.H.; Thakar, R. Is bladder Neck and urethral mobility associated with urinary incontinence and mode of delivery 4 years after childbirth? Neurourol. Urodyn. 2017, 36, 1403-1410. [CrossRef]

10. Karram, M.M.; Bhatia, N.N. The Q-tip test: Standardization of the technique and its interpretation in women with urinary incontinence. Obstet. Gynecol. 1988, 71, 807-811.

11. McGuire, E.J.; Lytton, B.; Pepe, V.; Kohorn, E.I. Stress Urinary Incontinence. Obstet. Gynecol. 1976, 47, 255-264. [PubMed]

12. Hanzal, E.; Joura, E.M.; Haeusler, G.; Koelbl, H. Influence of catheterisation on the results of sonographic urethrocystography in patients with genuine stress incontinence. Arch. Gynecol. Obstet. 1994, 255, 189-193. [CrossRef] [PubMed]

13. Hol, M.; van Bolhuis, C.; Vierhout, M.E. Vaginal ultrasound studies of bladder neck mobility. Br. J. Obstet. Gynaecol. 1995, 102, 47-53. [CrossRef] [PubMed] 
14. Pregazzi, R.; Sartore, A.; Bortoli, P.; Grimaldi, E.; Troiano, L.; Guaschino, S. Perineal ultrasound evaluation of urethral angle and bladder neck mobility in women with stress urinary incontinence. BJOG 2002, 109, 821-827. [CrossRef] [PubMed]

15. Van Geelen, H.; Ostergard, D.; Sand, P. A review of the impact of pregnancy and childbirth on pelvic floor function as assessed by objective measurement techniques. Int. Urogynecol. J. 2018, 29, 327-338. [CrossRef]

16. Naranjo-Ortiz, C.; Shek, K.L.; Martin, A.J.; Dietz, H.P. What is normal bladder Neck anatomy? Int. Urogynecol. J. 2016, 27, 945-950. [CrossRef] [PubMed]

17. Shek, K.L.; Kruger, J.; Dietz, H.P. The effect of pregnancy on hiatal dimensions and urethral mobility: An observational study. Int. Urogynecol. J. 2012, 23, 1561-1567. [CrossRef]

18. Dietz, H.P.; Eldridge, A.; Grace, M.; Clarke, B. Does pregnancy affect pelvic organ mobility? Aust. N. Z. J. Obstet. Gynaecol. 2004, 44, 517-520. [CrossRef]

19. Reed, H.; Freeman, R.M.; Waterfield, A.; Adekanmi, O. Prevalence of bladder Neck mobility in asymptomatic non-pregnant nulliparous volunteers. BJOG 2004, 111, 172-175. [CrossRef]

20. Peschers, U.M.; Fanger, G.; Schaer, G.N.; Vodusek, D.B.; DeLancey, J.O.; Schuessler, B. Bladder neck mobility in continent nulliparous women. BJOG 2001, 108, 320-324.

21. Tunn, R.; Albrich, S.; Beilecke, K.; Kociszewski, J.; Lindig-Knopke, C.; Reisenauer, C.; Schwertner- Tiepelmann, N.; Kuhn, A.; Viereck, V.; Bjelic Radisic, V.; et al. Interdisciplinary S2k guideline: Sonography in urogynecology: Short Version-AWMF registry number: 015/055. Geburtshilfe Frauenheilkd. 2014, 74, 1093-1098.

22. Wlazlak, E.; Kociszewski, J.; Suzin, J.; Dresler, M.; Surkont, G. Urethral length measurement in women during sonographic urethrocystography-An analysis of repeatability and reproducibility. J. Ultrason. 2016, 16, 25-31. [PubMed]

23. Whitcomb, E.L.; Lukacz, E.S.; Lawrence, J.M.; Nager, C.W.; Luber, K.M. Prevalence and degree of bother from pelvic floor disorders in obese women. Int. Urogynecol. J. Pelvic Floor Dysfunct. 2009, 20, 289-294. [CrossRef] [PubMed]

24. Dell'Atti, L.; Galosi, A.B. Female Urethra Adenocarcinoma. Clin. Genitourin. Cancer 2018, 16, e263-e267. [CrossRef] [PubMed]

25. Galosi, A.B.; Dell'Atti, L. Ultrasound Study of the Urethra. In Atlas of Ultrasonography in Urology, Andrology, and Nephrolog; Martino, P., Galosi, A.B., Eds.; Springer International Publishing: Cham, Switzerland, 2017; pp. 211-226.

26. Dietz, H.P.; Eldridge, A.; Grace, M.; Clarke, B. Pelvic organ descent in young nulligravid women. Am. J. Obstet. Gynecol. 2004, 191, 95-99. [CrossRef]

27. Dietz, H.P.; Hansell, N.K.; Grace, M.E.; Eldridge, A.M.; Clarke, B.; Martin, N.G. Bladder neck mobility is a heritable trait. BJOG 2005, 112, 334-339. [CrossRef]

28. Matthews, C.A.; Whitehead, W.E.; Townsend, M.K.; Grodstein, F. Risk factors for urinary, fecal, or dual incontinence in the Nurses' Health Study. Obstet. Gynecol. 2013, 122, 539-545. [CrossRef]

29. Rortveit, G.; Daltveit, A.K.; Hannestad, Y.S.; Hunskaar, S. Norwegian EPINCONT Study. Urinary incontinence after vaginal delivery or cesarean section. N. Engl. J. Med. 2003, 348, 900-907. [CrossRef]

30. Toozs-Hobson, P.; Balmforth, J.; Cardozo, L.; Khullar, V.; Athanasiou, S. The effect of mode of delivery on pelvic floor functional anatomy. Int. Urogynecol. J. Pelvic Floor Dysfunct. 2008, 19, 407-416. [CrossRef]

31. Dietz, H.P.; Bennett, M.J. The effect of childbirth on pelvic organ mobility. Obstet. Gynecol. 2003, 102, $223-228$. [CrossRef]

32. Zhu, L.; Lang, J.; Wang, H.; Han, S.; Huang, J. The prevalence of and potential risk factors for female urinary incontinence in Beijing, China. Menopause 2008, 15, 566-569. [CrossRef] [PubMed]

33. Townsend, M.K.; Danforth, K.N.; Rosner, B.; Curhan, G.C.; Resnick, N.M.; Grodstein, F. Body mass index, weight gain, and incident urinary incontinence in middle-aged women. Obstet. Gynecol. 2007, 110, 346-353. [CrossRef] [PubMed]

34. Khullar, V.; Sexton, C.C.; Thompson, C.L.; Milsom, I.; Bitoun, C.E.; Coyne, K.S. The relationship between BMI and urinary incontinence subgroups: Results from EpiLUTS. Neurourol. Urodyn. 2014, 33, 392-399. [CrossRef] [PubMed] 